\title{
A AVALIAÇÃO EM MÚSICA E SUA INFLUÊNCIA NO PROCESSO DE APRENDIZAGEM MUSICAL
}

Fernando Vieira da Cruz

Graduando em Música Lic. Pela UNOESTE - Universidade do Oeste Paulista. E-mail: fvccruz@hotmail.com

\section{RESUMO}

O presente artigo traz uma breve reflexão sobre avaliação em música e sua participação no processo da aprendizagem musical. As reflexões sobre avaliação em música estão baseadas em pesquisa teórica de autores da pedagogia e da educação musical. O objetivo do artigo é apresentar o modelo de avaliação, além de breve resumo da metodologia de ensino de $\mathrm{K}$. SWANWICK, renomado autor da educação musical do século XX. O modelo e conceitos apresentados versam sobre todo tipo de avaliação necessária em sala de aula, desde o primeiro dia de aula, passando por todo o processo de ensino e incluindo a tradicional verificação de aprendizagem.

Palavras-chave: Música. Educação Musical. Ensino. Aprendizagem. Avaliação.

\section{INTRODUÇÃO}

Em todas as circunstâncias da vida a aprendizagem, o desempenho e a avaliação se complementam. Isso ocorre tanto do ponto de vista acadêmico quanto na aplicação prática (BOTH, 2008).

De modo geral a avaliação torna possível a nossa vida, ao passo que em quase todos os momentos da vida processamos e passamos por processos de avaliação. Isso ocorre mesmo em tarefas comuns do dia a dia como, por exemplo, ao atravessar uma rua avaliamos a velocidade do tráfego da mesma e em outras diversas situações corriqueiras passamos por processos similares (SWANWICK, 2003).

No ponto de vista da educação musical, Swanwick defende que só é possível uma educação musical efetiva se junto dela houver uma avaliação musical genuína. Mas o autor ressalta ainda que muitas experiências de aprendizagem possam parecer não estar relacionadas a nenhum processo de avaliação, porém nesse momento Swanwick se refere a testes e exames formais.

É a partir desse ponto de vista que podemos iniciar nossa discussão a respeito do conceito de avaliação apresentado por esse autor, pois ele defende que a avaliação deve contribuir para o processo de aprendizado, sendo que a verificação de aprendizagem é apenas uma das abordagens da avaliação, que visa o resultado final da eficiência do trabalho do educador e não da capacidade de aprendizado do aluno. 


\section{A AVALIAÇÃO NO PROCESSO DE APRENDIZAGEM}

O laço entre os processos de aprendizagem, o desempenho e a avaliação vêm se estreitando sempre com o objetivo de entrelaçá-los no âmbito do conhecimento novo e na sua renovação (BOTH, 2008). BOTH (2008) defende a idéia de que é ensinando que se avalia e é avaliando que se ensina. Para o autor a avaliação e o processo de aprendizagem não só têm se aproximado, mas se fundido em suas funções de avaliar e ensinar, sendo que ambas são dependentes e se completam. $O$ ensino e a avaliação interagem na realidade, porém sem se tornarem distintos. É dessa forma que as novas abordagens e concepções de avaliação têm se apresentado em investigações científicas ou como experimentação prática. Essas novas modalidades avaliativas buscam saciar a necessidade de interação entre a avaliação e a aprendizagem BOTH (2008).

De acordo com SARAIVA (2005 apud BOTH, 2008) uma consideração importante a respeito da avaliação é que quando o educador avalia o aluno, coloca em avaliação também o ensino oferecido, sendo que o aluno terá sucesso em aprender tanto quanto o educador terá sucesso em ensinar. A autora diz:

"avaliar a aprendizagem do aluno significa, concomitantemente, avaliar o ensino oferecido [...] [assim,] se não houver a aprendizagem esperada, estamos diante de uma certeza - o ensino não cumpriu sua finalidade - a de fazer aprender" [...] um sistema de ensino comprometido com $o$ desenvolvimento das competências e habilidades dos alunos encontra na avaliação, não um instrumento para aprovar ou reprovar e, sim, uma referência à análise de seus propósitos, permitindo-lhes buscar caminhos para que os alunos sejam bem sucedidos na travessia da passarela da aprendizagem. (SARAIVA, 2005 apud BOTH, 2008, p. 27)

SARAIVA (2005 apud BOTH, 2008) coloca aqui o papel da avaliação inserida na função do sistema de ensino, ou seja, chegando a abandonar a idéia de verificação de aprendizagem - ainda que essa verificação continue sendo necessária - para dar à avaliação um papel fundamental durante o processo de aprendizagem do aluno. Durante esse processo, as linguagens, as abordagens, e até mesmo o sistema de ensino é que devem se adequar às necessidades do aluno, para que o processo de ensino e aprendizagem tenha sucesso.

Essa concepção de avaliação apresentada por SARAIVA (2005 apud BOTH, 2008) está relacionada às idéias apresentadas por SWANWICK (2003) quando se propõe a fundir a avaliação com o processo de aprendizagem vai ao encontro da resolução da problemática apresentada por 
DEMO (2007) que diz que não há uma didática que se relaciona diretamente ao interesse e à forma como os alunos lêem o mundo no século XXI.

\section{A AVALIAÇÃO “MUSICAL” DE KEITH SWANWICK}

Para SWANWICK (2003) as práticas de avaliação existentes podem ser aprimoradas criando caminhos mais eficazes para a avaliação musical. Porém para falarmos com profundidade das abordagens em avaliação de SWANWICK (2003) é necessário considerar que o autor tem uma visão da música como discurso através de metáforas. E isso acarreta várias conseqüências importantes para a educação musical. O autor apresenta três formas pelas quais entende que a música funciona por metáforas:

1. Transformamos sons em "melodias", gestos;

2. Transformamos essas "melodias", esses gestos, em estruturas;

3. Transformamos essas estruturas simbólicas em experiências significativas;

Podemos observar três estágios de compreensão musical, dadas pelo tipo de experiência, ou seja, por cada uma das três transformações apresentadas.

A primeira transformação se refere à fase inicial do desenvolvimento técnico de manipulação do instrumento musical, quando o aluno passa a ser capaz de transformar os primeiros sons que pode produzir com o instrumento musical em melodias simples.

À segunda fase podemos atribuir o entendimento de frases musicais completas, através das melodias manipuladas na fase anterior. Essa é uma experiência um pouco mais complexa, se considerarmos que para uma frase musical com sentido completo é na maioria das vezes, necessário utilizarmos mais de uma melodia de sentido curto. Assim teremos um sentido ou significado único atribuído a duas, três ou mais melodias.

Já a terceira fase é apresentada como experiência significativa, pois é a transformação de várias frases musicais em estruturas mais complexas, e outras o aluno terá uma compreensão ampliada, passando por notas soltas, melodias curtas, frases solitárias e chegando a compreensão de formas musicais mais intrincadas, como por exemplo, as formas $A B, A A B B$ e etc.

Além das três transformações apresentadas, SWANWICK (2003) ainda apresenta três princípios de ação em educação musical.

O primeiro princípio é considerar a música como discurso, e nele já estão inseridos as três transformações apresentadas, "Um dos objetivos do professor é trazer a consciência musical do último para o primeiro plano" (SWANWICK, 2003, p.57). 
O segundo princípio é considerar o discurso musical dos alunos. Para tanto precisamos levar em conta o conhecimento musical que o aluno possui. Estando o aluno em qualquer uma das fases de transformação é necessário se considerar o discurso dele, para que possamos inclusive avaliar - identificar - em que fase de compreensão o aluno efetivamente está inserido para encaminhá-lo a uma compreensão mais complexa.

O terceiro princípio é a fluência musical do início ao fim. Assim como outros educadores musicais inseridos neste mesmo cenário como George Self, John Paynter, Boris Porema e Murray Schafer, Swanwick valoriza o afastamento de procedimentos técnicos ou teóricos, preferindo que o contato com a música seja como uma experiência de vida, ou seja, valorizando mais a vivência musical.

Segundo FONTERRADA (2008) a criança passa por cada nível de transformação de maneira sucessiva aos blocos "material", "expressão", "forma" e "valor" experimentando cada proposta inicialmente de forma intuitiva e depois analítica.

Figura 1. À esquerda e à direita da espiral

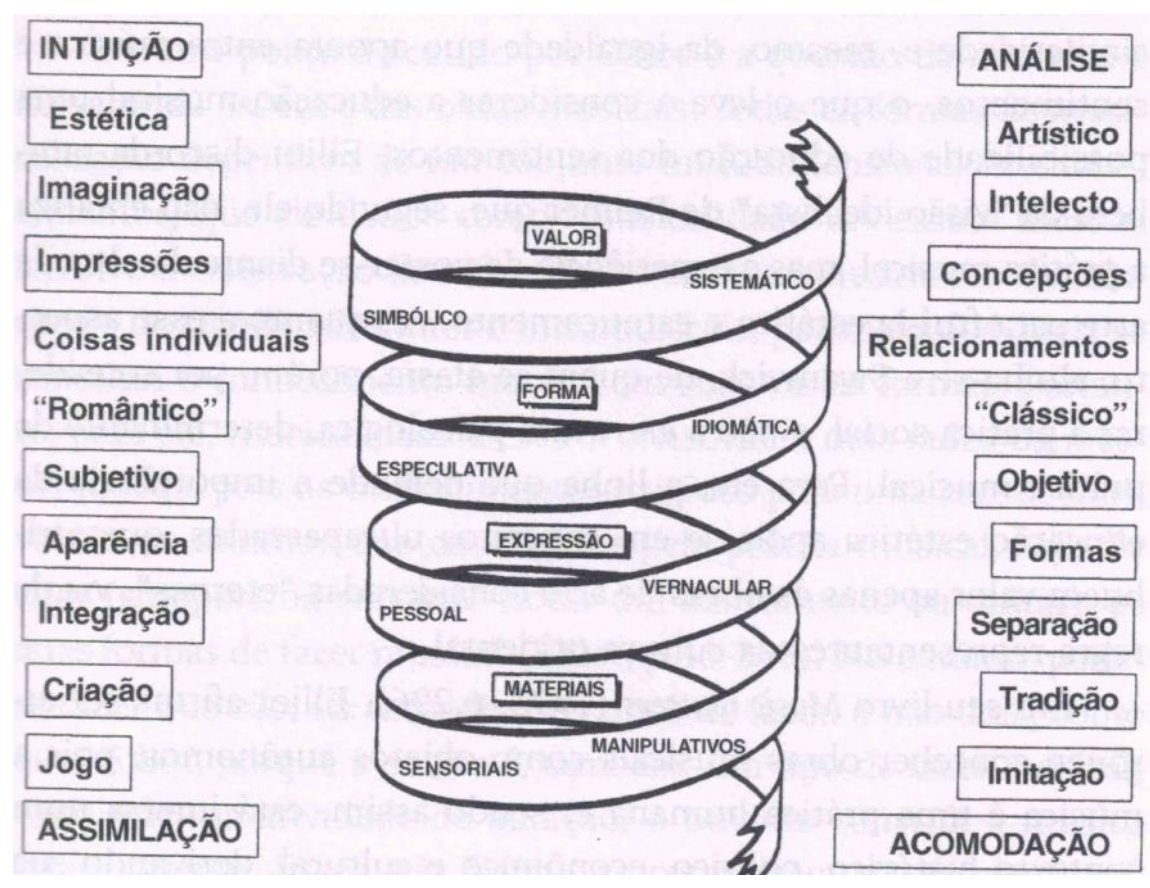

Fonte: SWANWICK,1994 apud FONTERRADA, 2008, p. 113

A figura espiral nos dá a idéia de que conforme o aluno passa pelas fases de transformação, ele não abandona as experiências anteriores, sendo que de maneira espiral sempre acaba passando novamente de certa forma pelas experiências anteriores.

Considerando as três transformações apresentadas por SWANWICK (2003) como fases ou estágios de compreensão musical, e, embasados nos três princípios de ação pedagógica musical 
podemos entender o que Swanwick chama de avaliar musicalmente, ou seja, inserir processos de avaliação musical no decorrer do desenvolvimento da aprendizagem do aluno.

\section{CONCLUSÃO}

As três transformações e os três princípios apresentados por SWANWICK (2003) servem de base e de parâmetro para uma avaliação musical continua e efetiva. A proposta de SWANWICK (2003) está alinhada aos Parâmetros Curriculares Nacionais do Brasil de 1997 que a respeito da avaliação em artes diz que a mesma deve ser realizada em três momentos (BRASIL, 1997, p. 102):

(1) A avaliação pode diagnosticar o nível de conhecimento dos alunos. Nesse caso costuma ser prévia de uma atividade; (2) A avaliação pode ser realizada durante a própria situação de aprendizagem, quando o professor identifica como o aluno interage com os conteúdos; (3) A avaliação pode ser realizada ao término de um conjunto de atividades que compõem uma unidade didática para analisar como a aprendizagem ocorreu (BRASIL, 1997, p. 102).

Cumprindo assim a avaliação três funções: Em primeiro a avaliação diagnóstica, com a função de diagnosticar conhecimentos prévios musicais do aluno, conhecimentos estes desenvolvidos em experiências anteriores que o aluno vivenciou em espaços formais ou não formais de aulas de música, ou ainda por meios de comunicação, tornando-se a avaliação de fundamental importância para se determinar um ponto de partida nas ações pedagógicas com o aluno avaliado. Em segundo lugar temos a avaliação formativa, com o papel de acompanhar todo o processo de aprendizagem do aluno, servindo assim de parâmetro para adequação do espaço ou abordagem usada, visando atingir a modalidade de ensino - ou abordagem- que com maior eficácia cumprirá neste caso específico o papel de fazer aprender. Em terceiro lugar temos a avaliação somativa ou final, apesar de ter essa avaliação um papel próximo da verificação de aprendizagem, não se espera que através dela se atribua notas, ou sentenças de aprovado ou reprovado ao aluno, mas serve esta modalidade de avaliação principalmente para avaliar o quanto foi eficaz o ensino (BOTH, 2008), o método, ou o educador.

O papel da avaliação musical no século XX e nos dias atuais em muito se difere das práticas do século XIX onde a educação musical estava profundamente ligada à execução musical virtuose, com base na técnica e na leitura musical, sendo que a avaliação tinha um caráter formal e era realizada através de testes e audições formais, situações em que se atribuía uma nota ao domínio técnico desenvolvido pelo aluno, bem como lhe era dada a sentença de aprovado ou reprovado. 
Porém com as transformações ocorridas na educação musical do século $X X$, a partir de quando o que se valoriza no processo de aprendizagem musical é exatamente o contato com a música como uma experiência de vida, ou seja, valorizando mais a vivência musical e se afastando de procedimentos técnicos ou teóricos, a avaliação passa a cumprir um papel essencial de apoio ao processo de ensino e aprendizagem musical.

\section{REFERÊNCIAS}

José Both, I. Avaliação planejada, aprendizagem consentida: é ensinando que se avalia, é avaliando que se ensina. 2. ed. rev. e ampl. Curitiba: Ibpex, 2008.

Demo, P. O Porvir: desfio das linguagens do século XXI. 20. ed. Curitiba: Ibpex, 2007.

Trench de Oliveira Fonterrada, M. De tramas e fios: um ensaio sobre música e educação. 2.ed. São Paulo: Editora UNESP, 2008.

Swanwick, K. Ensinando música musicalmente. tradução de Alda Oliveira e Cristina Tourinho. São Paulo: Moderna, 2003.

BRASIL, Secretaria de Educação Fundamental. Parâmetros Curriculares Nacionais: arte/Secretaria de Educação Fundamental. Brasília: MEC/SEF, 1997. 